\title{
Relationship Between CRP and a Lin Routine Abdominal Procedures: A Systematic Analysis
}

\author{
1. Dr. ShamimaNasrin, \\ MBBS, FCPS (Surgery), FMAS \\ Assistant Professor Surgery \\ Ad-din Women's Medical College \& Hospital, Dhaka, \\ Bangladesh \\ Dr. Md. Musab Khalil \\ MRCP(UK), MD (Gastroenterology), \\ Assistant Registrar, \\ Sheikh Russel National GastroliverInstitue and Hospital, \\ Mohakhali, Dhaka
}

\author{
2. Dr. Mir RasekhAlamOvi, MBBS, \\ FCPS (Surgery) ,FMAS \\ Consultatnt, Surgery \\ General Hospital, Narayangonj, Dhaka \\ Bangladesh
}
4. Dr. FarhanImtiaz Chowdhury, MBBS, FCPS (Surgery), Registrar Surgery
Rajshahi Medical College Hospital Rajshshi.

\begin{abstract}
:-
\section{$>$ Background:}

Anastomotic leakage (AL) is the most drastic complication specific to intestinal surgery, but it is frequently diagnosed late. Early diagnosis and prompt treatment can reduce morbidity and mortality. The aim of the study was to evaluate the diagnostic accuracy of serial $\mathbf{C}$ - reactive protein (CRP) in early detection of anastomotic leakage in routine abdominal procedures.
\end{abstract}

\section{Methodology:}

The study was conducted over a period of 1 year from $1^{\text {st }}$ January 2015 to $31^{\text {th }}$ December 2015 in the Department of Surgery of DMCH. Within the period, 100 patients were prospectively selected for the study irrespective of age and sex. CRP of all patients was measured on $3^{\text {rd }}$ and $5^{\text {th }}$ post operative day (POD). Data was collected through questionnaire.

\section{Result:}

27 patients had anastomotic leakage. Mean age of the leakage and non leakage were $44.77 \pm 15.00$ and $48.09 \pm$ 13.68 years respectably $(p=0.308)$. There was male predominance in both the groups.Most $(55 \%)$ of the anastomotic leakage (AL) occurred in the pancreaticojejunostomy patients. In $3^{\text {rd }}$ post operative day (POD) the mean \pm SD CRP with the anastomotic leakage (AL)group and non-anastomotic leakage(non AL)group were $180.88 \pm 61.63$ and $96.65 \pm 44.76(p<.0001)$. In $5^{\text {th }}$ post operative day (POD) the mean CRP of anastomotic leakage(AL) and non anastomotic leakage (non-AL) were consecutively $121.18 \pm 33.64$ and $45.60 \pm 28.71$ (p<.0001). Cutoff value for CRP of $143 \mathrm{mg} / \mathrm{l}$ on POD 3 was associated with development of anastomotic leakage (AL).

\section{$>$ Conclusion:}

Patients with CRP levels at or below $143 \mathrm{mg} / \mathrm{l}$ on POD 3 can be safely discharged after elective abdominal surgery.

Keywords:- Anastomotic Leakage, CRP, Abdominal Surgery.

\section{INTRODUCTION}

A significant complication after resection and reconstruction of the gastrointestinal tract is anastomotic leakage $(\mathrm{AL})$. The prevalence of $\mathrm{AL}$ identified ranges from 1 to $39 \% .^{1-3}$ Among these patients, morbidity, mortality and costs are higher and hospital stays are longer. Alveset al. ${ }^{4}$ demonstrated that in patients with AL, the mortality rate after elective large bowel resection was substantially higher than in those without $\mathrm{AL}(13 \%$ vs. $1 \%)$. As there are no clear and early signs or symptoms of AL, patients with signs and symptoms of peritonitis and sepsis or systemic symptoms are often diagnosed late in the postoperative period $^{5}$. It is necessary to diagnose this complication early, because of the global trend towards faster discharge of surgical patients. In order to detect inflammatory behavior postoperatively, several biochemical tests have been suggested, including serum levels of C-reactive protein (CRP), procalcitonin, interleukin and count of white blood cells (WBCs) ${ }^{6,7}$. Because of their simplicity and low cost, CRP level and WBC count have been commonly used. Since CRP is a short-lived (19 h) non-specific inflammatory mediator, it is a valuable marker for most forms of inflammation, infection, tissue damage, and malignant neoplasia. $^{8}$

Several studies have shown that, as opposed to an early peak followed by a fall, a sustained rise in the CRP level after surgery precedes the incidence of $\mathrm{AL}^{9-11}$. Creactive protein (CRP) has been examined in abdominal surgery as an indication of postoperative septic and surgical complications, but leakage risk factors are not completely 
known and leakage is difficult to predict in individual patients. Anastomotic ischaemia, stress and presacralhaematoma or aggregation of fluid with subsequent infection are suggested mechanisms. In a few studies, ischaemia has been examined and is associated with an increased risk of leakage.

Anastomosis stress is widely accepted as a risk factor, but this is hard to prove. The mesentery can become thickened and shortened by continued intra-abdominal inflammation. It may be that the postoperative inflammatory reaction causes the colonic neo-rectum mesentery to shorten, resulting in leakage anastomosis strain.

An accurate early indicator of anastomotic leakage is therefore needed, particularly in an era of fast-track recovery in which patients are discharged earlier from the hospital and potentially before any clinical signs of leakage develop. Therefore, this study is designed to evaluate the value of the diagnostic accuracy of serial CRP in the early prediction of anastomotic leakage. In abdominal surgery, surgeons lack predictive precision for anastomotic leakage. Morbidity increases when treatment of anastomotic leakage is postponed. Thus, particularly in the era of fast track surgery, the early diagnosis of anastomotic leak is warranted. Provided that it is cost-effective and responsive enough to allow safe discharge, a serum marker would have great benefits. In addition, early detection of anastomotic leakage would allow surgeons to take appropriate action even before it becomes clinically evident and will therefore mitigate dreadful complications.

A serious complication following colorectal surgery is anastomotic leakage (AL). The reported prevalence ranges from about $1 \%$ to $39 \%$. Since no standardized definition exists, it is difficult to compare ${ }^{1}$. Major postoperative morbidity, increased mortality, extended hospital stay, and additional costs lead to anastomotic leakage. AL has been shown to have an independent detrimental effect on longterm survival after potentially curative resection of colorectal cancer, in addition to these early consequences. Several studies have reported several independent risk factors, such as the score of the American Society of Anesthesiologists (ASA), operating time, the need for blood transfusion, the distance from anastomosis to the anal boundary, and septic conditions intraoperative $2-5,10$. Protective stoma should be considered in patients at high risk for AL and such patients should be closely monitored postoperatively ${ }^{4},{ }^{11}$. Since a delay in relaparotomy for AL can increase mortality in patients with peritonitis, early detection of $\mathrm{AL}$ is desirable ${ }^{12,13}$. In acute pancreatitis and pancreatic transplantation, increased levels of C-reactive protein have already been identified for signaling an adverse outcome and for early detection of necrosis ${ }^{14,15}$. In addition, this pentameric protein is considered an indication of surgical complications after surgery.

\section{MATERIALS AND METHODS}

Surgeons lack predictive accuracy for anastomotic leakage in abdominal surgery. Morbidity increases when there is delay in treating anastomotic leakage. The early diagnosis of anastomotic leak is thus warranted, particularly in the era of fast track surgery. A serum marker would have great advantages provided that it is cost effective and sensitive enough to allow safe discharge. Furthermore, early prediction of anastomotic leak will allow the surgeons to take appropriate measures even before it becomes clinically apparent and thus dreadful complications can be minimized. This study was designed to evaluate the value of the diagnostic accuracy of serial CRP in the early prediction of anastomotic leakage potentially before developing any clinical signs of a leak. The study was conducted over a period of 1 year (i.e. $1^{\text {st }}$ January 2015 to $31^{\text {th }}$ December 2015) in the Department of Surgery of DMCH. Within the period, 100 patients were prospectively selected for the study irrespective of age and sex. Data was collected through questionnaire.Detail history was taken from all patients.Clinical examination was done methodically. Pre-operative evaluation for fitness for surgery is evaluated both clinically and by lab investigations. All surgeries were done by specialist surgeons. Patient demographics (age and sex), surgical indications, operative details, blood transfusion, defunctioningstoma, type of anastomosis, type of surgerywere recorded. Only elective surgeries e.g. Partial Gastrectomy with Gastrojejunostomy, Choledocoduodenostomy, Pancreaticojejunostomy, Right Hemicolectomy, Left Hemicolectomy, Anterior resection with Colorectal Anastomosis were included. Mechanical bowel preparation was used routinely.All procedures were performed using an open approach.Laparoscopic surgeries were excluded because it is not aroutine technique at our hospital. Reconstruction was performedwith either handsewn or stapled anastomosis. All anastomosis were routinely drained. The patients received antibiotic (secondgeneration cephalosporin and metronidazole) preoperative, and postoperatively. AL was defined by clinical signs of peritonitis and /or clinical evidence of free fecal fluid within the abdomen or emerging from the drain site.Clinical manifestations were fever, abscess, septicemia, peritonitis, and/or organ failure. No imaging was performedroutinely to search for leakage.Postoperative complications were recorded as infectiousand non-infectious during the hospital stay after surgery.Infectious complications were classified as $\mathrm{AL}$ and remote infection. AL was defined by clinical signs of peritonitis and /or clinical evidence of free fecal fluid within the abdomen or emerging from the drain site. No imaging was performedroutinely to search for leakage. CRP were ordered for all patients in $3^{\text {rd }}$ and $5^{\text {th }}$ POD. Those who developed anastomotic leakage were managed according to their type and severity. 


\section{RESULT}

To determine the diagnostic accuracy of CRP, receiver operating characteristics (ROCs) curve analysis was used. This method calculates the sensitivity and specificity of each test outcome observed with regard to a given classification variable, defining the highest sensitivity and specificity cutoff value for CRP. The ROC curve is obtained by plotting sensitivity (fraction of true positives, $y$-axis) against 1-specificity (fraction of false negatives, x-axis). A 50 percent AUC value indicates the ability of the test to differentiate substantially between positive and negative cases with respect to the classification variable (e.g., disease presence or absence). An AUC test[0.80] was considered to have high diagnostic accuracy, suggesting that at least $80 \%$ of patients with the disease were correctly identified. A p 10.05 (two-sided test) value was found to be statistically important.

\begin{tabular}{|c|c|c|c|}
\hline & & & Leakage, $\mathbf{n = 2 7}$ \\
\hline Age distribution & No leakage, $\mathbf{n = 7 3}$ & 1 & 3 \\
\hline$<25$ & 2 & 4 & 10 \\
\hline $25-31$ & 6 & 7 & 19 \\
\hline $32-37$ & 12 & 5 & 15 \\
\hline $38-44$ & 10 & 2 & 13 \\
\hline $45-51$ & 11 & 3 & 16 \\
\hline $52-57$ & 13 & 2 & 16 \\
\hline $58-64$ & 14 & 1 & 4 \\
\hline $72-77$ & 3 & 2 & 3 \\
\hline $78+$ & 1 & 0 & 1 \\
\hline Mean \pm SD* & 1 & $48.09 \pm 13.68$ & $47.20 \pm 14.05$ \\
\hline
\end{tabular}

Table 1:- Age distribution of participants

$$
* \mathrm{p}=0.3082
$$

Table I shows the age distribution of the patients. Mean age of the leakage and No leakage were $44.77 \pm 15.00$ and $48.09 \pm$ 13.68 years respectably. As the $\mathrm{p}=0.3082$ so by conventional criteria, this difference is considered to be not statistically significant.

\begin{tabular}{|c|c|c|c|}
\hline Surgery & No leakage, $\mathbf{n = 7 3}$ & Leakage, $\mathbf{n = 2 7}$ & Total \\
$\mathbf{N = 1 0 0}$
\end{tabular}

Table 2:- Type of surgery

Table II shows Highest number of patients (28) underwent partial gastrectomy with gastrojejunostomy followed by pancreaticojejunostomy (18 patients)

\begin{tabular}{|c|c|c|c|}
\hline Type & No leakage, $\mathbf{n}=\mathbf{7 3}$ & Leakage, $\mathbf{n = 2 7}$ & Total, $\mathbf{n = 1 0 0}$ \\
\hline Hand Sewn & $49(67 \%)$ & $24(89 \%)$ & $73(73 \%)$ \\
\hline Mechanical & $24(33 \%)$ & $3(11 \%)$ & $27(27 \%)$ \\
\hline
\end{tabular}

Table 3:- Type of Anastomosis

Chi squared equals 3.697 with 1 degrees of freedom. The two-tailed P value equals 0.05 .

$49(67 \%)$ patients with no leakage was hand sewn. The association between rows (types) and columns (outcomes) is considered to be not quite statistically significant. 


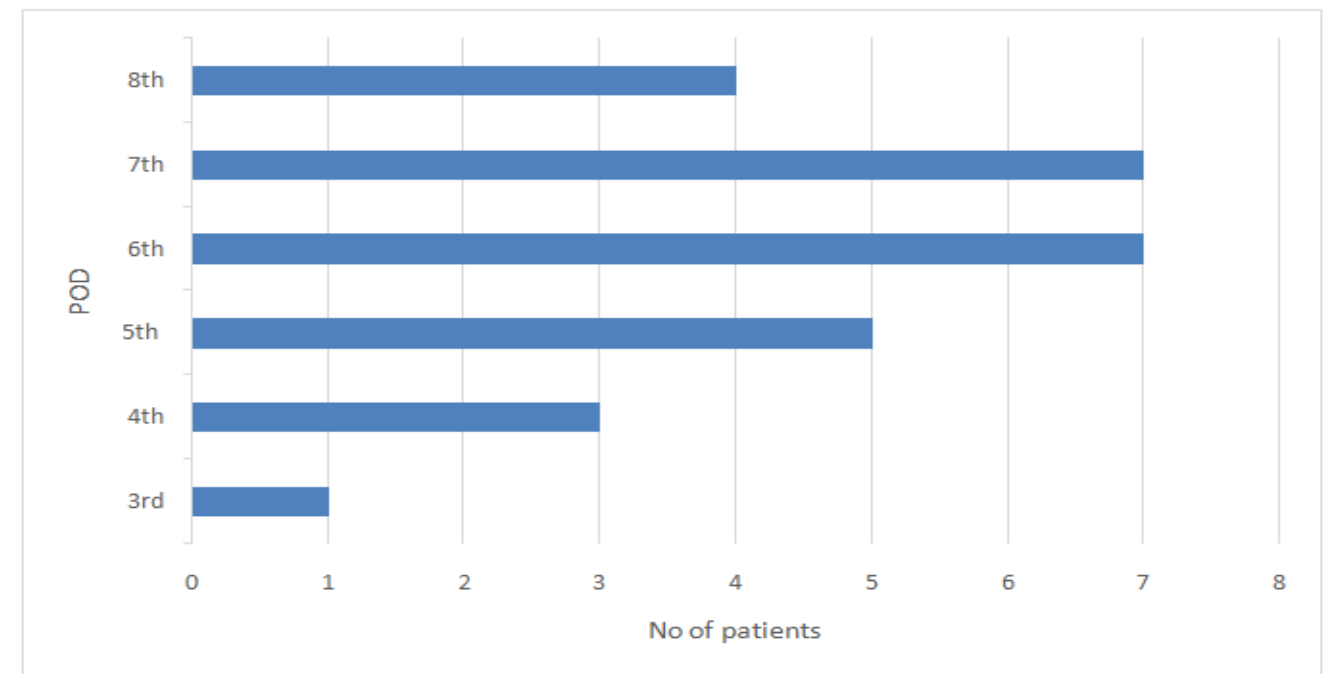

Fig 1:- Anastomotic leakage according to POD (n=27)

Most of the patients were diagnosed in $6^{\text {th }}$ and $7^{\text {th }}$ POD. ( 7 patients each). Early diagnosis was in $3^{\text {rd }}$ POD (1 patient).

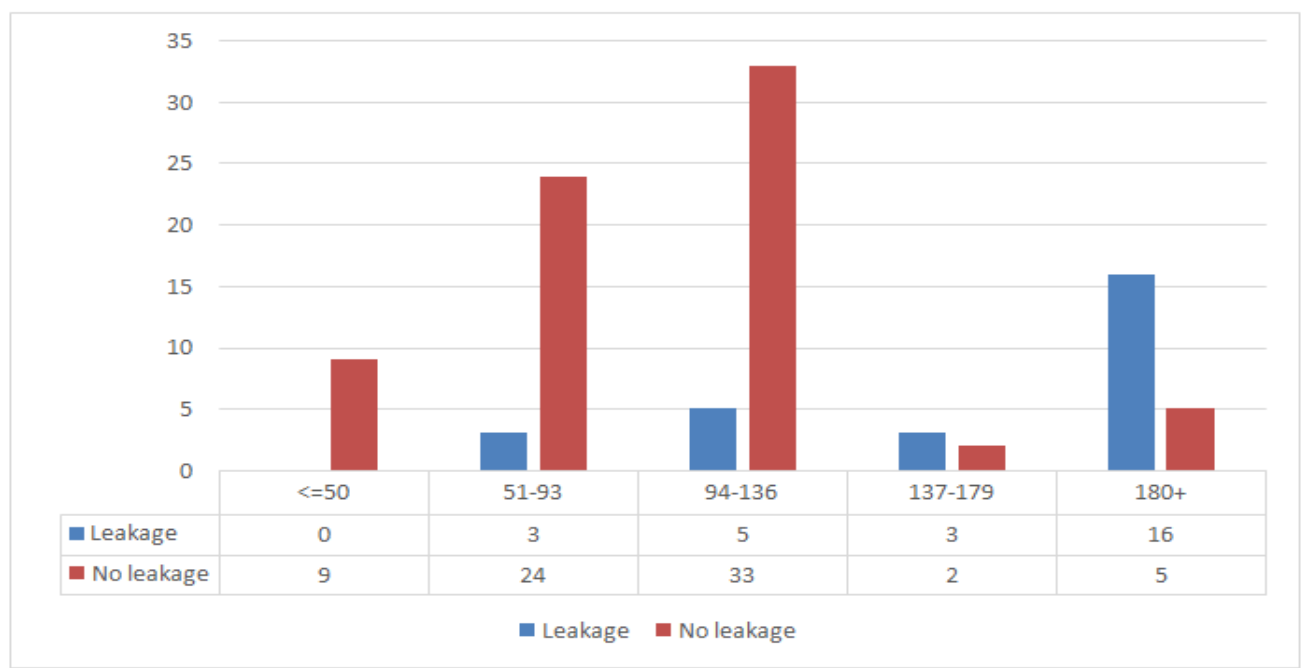

Fig 2:- CRP on $3^{\text {rd }}$ POD and anastomotic leakage

Figure 2 reveals that most patients $(\mathrm{n}=18)$ who had anastomotic leakage had CRP level of $>180$ in $3^{\text {rd }}$ POD.

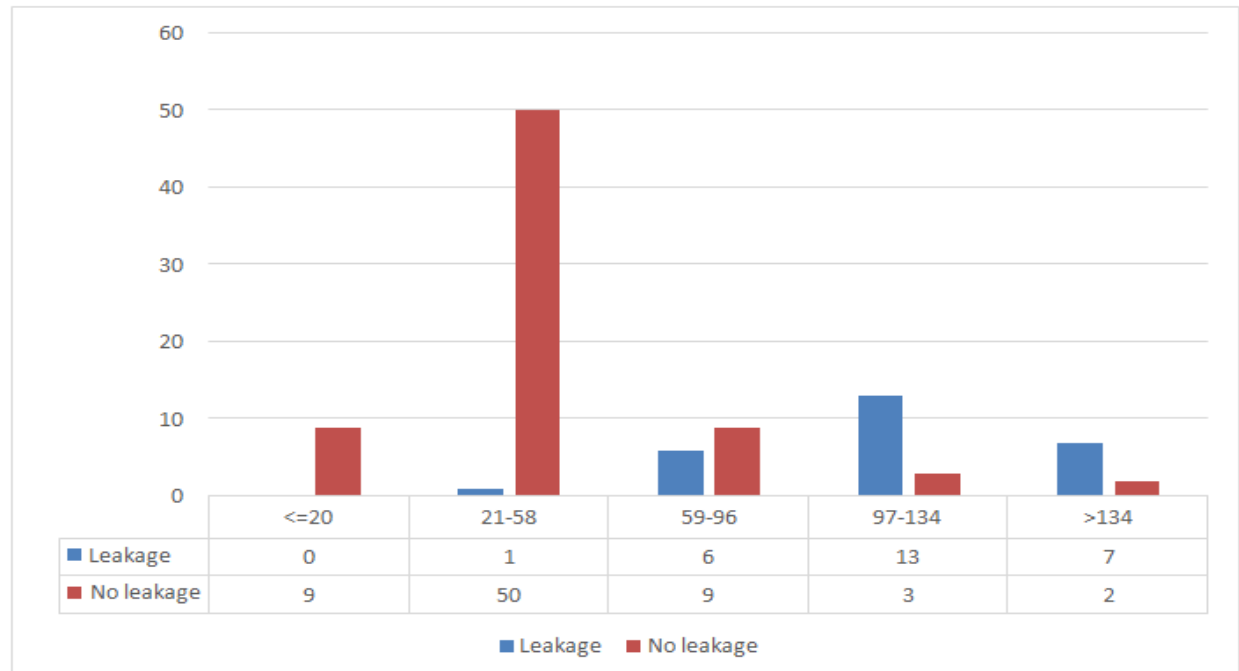

Fig 3:- CRP on $5^{\text {th }}$ POD and anastomotic leakage, reveals that most patients $(n=13)$ who had anastomotic leakage had CRP level in between $97-134$ in $5^{\text {th }}$ POD. 
ISSN No:-2456-2165

\begin{tabular}{|c|c|c|c|c|c|c|}
\hline CRP & Leakage & Mean & $\mathbf{N}$ & Std. Deviation & Maximum & Minimum \\
\hline \multirow[t]{3}{*}{$3^{\text {rd }}$ POD } & Yes & 180.888 & 27 & 61.634 & 77 & 265 \\
\hline & No & 96.657 & 73 & 44.765 & 25 & 247 \\
\hline & Total & 119.400 & 100 & 62.190 & 25 & 265 \\
\hline \multirow[t]{3}{*}{$5^{\text {th }}$ POD } & Yes & 121.185 & 27 & 33.647 & 55 & 175 \\
\hline & No & 45.602 & 73 & 28.714 & 11 & 168 \\
\hline & Total & 66.01 & 100 & 45.103 & 11 & 175 \\
\hline
\end{tabular}

Table 4:- CRP on $3^{\text {rd }} \& 5^{\text {th }}$ POD Vs Leakage

In case of $3^{\text {rd }} \mathrm{POD}, \mathrm{t}=11.1475, \mathrm{df}=98$, standard error of difference $=6.780$. The mean of Group One minus Group Two equals 75.58300. 95\% confidence interval of this difference: From 62.12777 to 89.03823. In case of $5^{\text {th }} \mathrm{POD}, \mathrm{t}=7.5090, \mathrm{df}=98$, standard error of difference $=11.217$. The mean of Group One minus Group Two equals 84.23100. 95\% confidence interval of this difference: From 61.97053 to 106.49147. In both cases the two-tailed P value is less than 0.0001.By conventional criteria; this difference is considered to be extremely statistically significant.

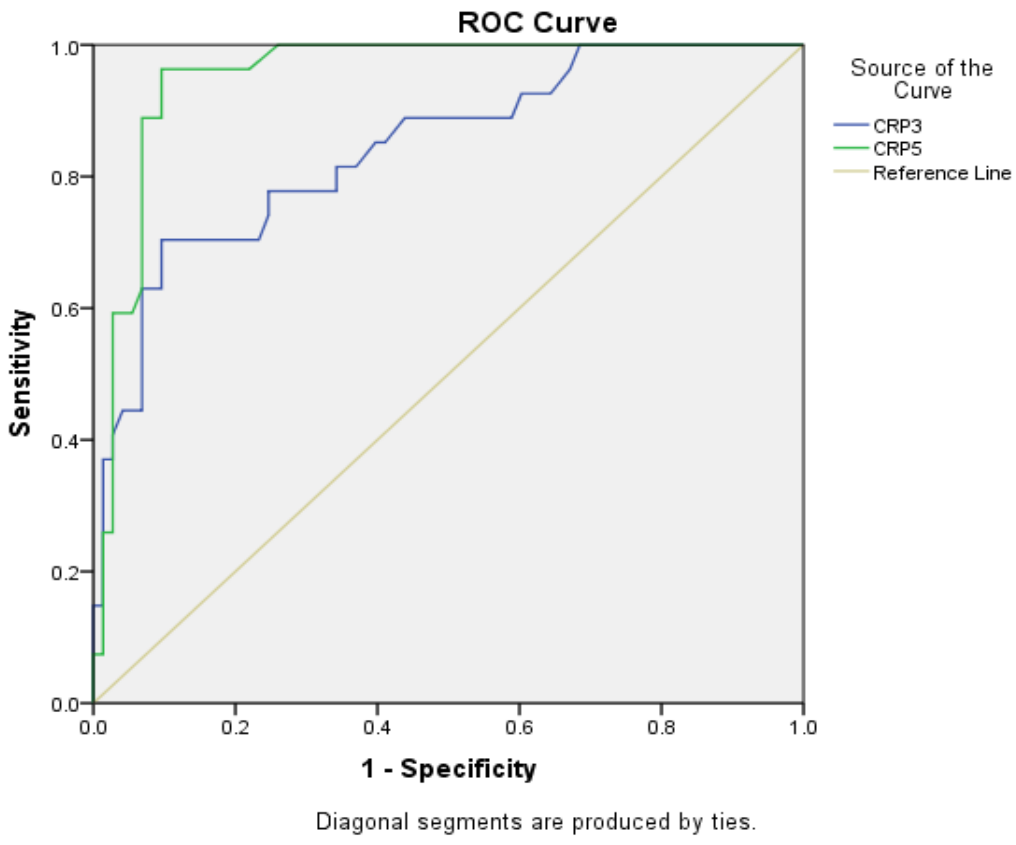

Fig. 4:- Diagnostic accuracy of CRP with regard to development of anastomotic leakage after elective abdominal surgery as expressed by the ROC curve. Comparison of ROC curves for POD 3, POD 5 with respective area under the curve values of 0.843 and 0.952

\begin{tabular}{|c|c|c|c|c|}
\hline CRP & Cut off value & Sensitivity & Specificity & AUC (95\% CI) \\
\hline $3^{\text {rd }}$ POD & 143 & 70 & 90 & 0.843 \\
\hline $5^{\text {th }}$ POD & 101 & 63 & 93 & 0.952 \\
\hline
\end{tabular}

Table 5:- ROC curve analysis of CRP

ROC $=$ Receiver operating characteristics,

$\mathrm{CRP}=\mathrm{C}$-reactive protein

AUC $=$ Area under the curve, $\mathrm{CI}=$ Confidence interval

Table V showed that a cutoff value for CRP of 143 $\mathrm{mg} / \mathrm{l}$ on POD 3 is associated with development of AL, with sensitivity of $70 \%$ and specificity of $90 \%$ and with good diagnostic accuracy of $84.3 \%$ and in $5^{\text {th }}$ POD a cutoff value for CRP of $101 \mathrm{mg} / \mathrm{l}$ is associated with development of AL, with sensitivity of $63 \%$ and specificity of $93 \%$ and with good diagnostic accuracy of $95.2 \%$.

\section{DISCUSSION}

The most critical complication unique to intestinal surgery is anastomotic leakage (AL), but it is frequently detected late, often after patients have been discharged from the hospital. Diagnosis of AL after postoperative day 5 is associated with a mortality rate of $18 \%$, according to Alves et al[1], compared to $0 \%$ when diagnosed before POD 5 . Therefore, prior to its clinical presentation, it is important to detect AL.In our study, most of the patients were diagnosed in $6^{\text {th }}$ and $7^{\text {th }}$ POD (7 patients each). Early diagnosis was in 
$3^{\text {rd }}$ POD (1 patient). We clinically confirmed $\mathrm{AL}$ at a median of $6 \pm 1.32$ days.

Some patients may have had a subclinical leak, but these patients typically do not need surgical intervention and are not of clinical significance. The heterogeneity of the sample population is the drawback of the present analysis. The goal, however, was to determine whether AL causes the level of CRP to increase, regardless of the type of surgery performed. It is understood that CRP is not unique to a specific organ site or surgical procedure. After esophageal, pancreatic, and colorectal resections, it is described as an early predictor of septic complications. Oh, [7,8,17,18].

Table I shows the age distribution of the patients. Mean age of the leakage and No leakage were $44.77 \pm 15.00$ and $48.09 \pm 13.68$ years respectably. As the $p=0.3082$ so by conventional criteria, this difference is considered to be not statistically significant. The mean age was little lower (median 65 years) than M. S. Scepanovic et al [26] found. It may be due to early diagnosis of the disease or change of disease epidemiology in our country. There waslittle male predominance in both the group.M. S. Scepanovic et al [26] had $57.1 \%$ male population which is nearly to our study $(61 \%)$. As male are the privileged group in our society so this finding is acceptable. This data is not given in the tabulated form. 28 patients underwent partial gastrectomy with gastrojejunostomy followed by pancreaticojejunostomy (18 patients). Most (55\%) of the AL occurred in the pancreaticojejunostomy patients. 73 patients was hand sewn anastomosis while 27 dad mechanical devices. 49 (67\%) patients with no leakage was hand sewn. No statically significance was found between these two types. The result is similar what M. S. Scepanovic et al [26] found. They had $75 \%$ hand sewn anastomosis. Most patients $(n=18)$ who had anastomotic leakage had CRP level of $>180$ in $3^{\text {rd }}$ POD. On the other hand in $5^{\text {th }}$ POD patients $(n=13)$ who had anastomotic leakage had CRP level in between 97-134. In our study the mean CRP in $3^{\text {rd }}$ POD with the AL group was $180.88 \pm 61.63$. It is statistically significant $(\mathrm{p}<.0001)$ with the non-AL group (mean=96.65 \pm 44.76 ). In $5^{\text {th }}$ POD the mean CRP of AL and non-AL were consecutively $121.185 \pm 33.64$ and $45.60 \pm 28.71 \quad(p<.0001)$. M. S. Scepanovic et al [26] found CRP median of 111 in $3^{\text {rd }}$ POD and 56 in $5^{\text {th }}$ POD in there study which were very close to our study. While WarschkowR at al [26] had similar value of CRP in colorectal 794.M. S. Scepanovic et al [26] found CRP was significantly higher in patients who developed AL. They found that a CRP cutoff value of $135 \mathrm{mg} / 1$ on POD 3 is associated with AL growth, with 73 percent sensitivity and 73 percent specificity, and 73.8 percent good diagnostic accuracy. $95.4 \%$ of patients with a CRP value of $135 \mathrm{mg} / 1$ on POD 3 do not develop AL in the postoperative period due to a very high negative predictive value. This argument is also backed by other reports. Welsh et al.[26] concluded that serum CRP levels in POD 3-4 above $140 \mathrm{mg} / 1$ are predictive of infectious complications and that CRP is a delicate yet non-specific marker.Korner et al.[18] found that in 4 out of 5 patients, an elevated CRP level of $190 \mathrm{mg} / 1$ or more on POD 3 after all forms of colorectal surgery was correlated with AL. MacKay et al.[21] suggest that a 145 mg / 1 CRP cutoff value for POD 4 may have sufficient sensitivity and specificity for infectious complications after elective colorectal resection. Ortega-Deballon et al.[20] concluded that it is possible to safely discharge patients with CRP values of $125 \mathrm{mg} / \mathrm{l}$ on POD 4 from the hospital.Warschkow et al.[23] proposed that CRP on POD 4 be measured. The authors suggested looking for inflammatory complications for CRP values above $123 \mathrm{mg} /$ 1. We found that a cutoff value for CRP of $143 \mathrm{mg} / 1 \mathrm{on}$ POD 3 is associated with AL development, with a sensitivity of 70 percent and a specificity of 90 percent and with a good diagnostic accuracy of 84.3 percent, and a cutoff value for CRP of $101 \mathrm{mg} / \mathrm{l}$ in the 5th POD is associated with AL development, with a specificity of 90 percent and a good diagnostic accuracy of 84.3 percent. These results are similar to the claims of the studies referred to above.Dutta et al.[22] suggested that a CRP level between 170 and $190 \mathrm{mg} / \mathrm{l}$ on POD 3 and POD 4 is indicative of the development of $\mathrm{AL}$ following esophagogastriccancer resection.If we compare patients with and without AL, CRP was significantly higher in patients who developed AL.

Elevated CRP can also cause infectious complications. In relation to CRP, this research did not distinguish between $\mathrm{AL}$ and infectious complications. To find an accurate cutoff value of CRP, a further analysis that minimizes this distance may be more feasible. The patient was not tracked by this research until the end. To establish the relationship of CRP with individual surgeries, a broader study duration with more variables would also be beneficial. To evaluate the actual scenario, a non-purposive one with a greater sample size may also be useful.

\section{CONCLUSION}

Even before the defect becomes clinically evident, conducting early examinations in response to persistently high CRP levels can help to detect AL. Our findings support the function, even after all the limitations, of serum CRP as a valuable tool for surgeons in postoperative clinical assessment. Early feeding can be prescribed to patients with CRP levels of $143 \mathrm{mg} / 1$ for POD 3, and early discharge can be scheduled to minimize the overall cost of care.In addition, the incidence of anastomotic leakage after elective abdominal surgery is followed by a sustained elevation in the CRP level with no corresponding decrease. They should be closely monitored and examined with water soluble x-ray contrast and preserved for a longer period of time with NPO.

\section{ACKNOWLEDGMENT}

The authors would like to thanks Dr.A B M Jamal, Professor of Surgery of Dhaka Medical College for his guidance in conducting the study. The authors would also like to thank Director of Dhaka Medical College for his support in conducting the study. 


\section{REFERENCES}

[1]. Alves A, Panis Y, Trancart D, Regimbeau JM, Pocard M, Valleur P. Factors associated with clinically significant anastomotic leakage after large bowel resection: multivariate analysis in 707 patients. World J Surg. 2002; 26:499-502.

[2]. Bruce J, Krukowski ZH, Al-KhairyG, Russell EM, ParkKG. Systematic review of the definition and measurement of anastomotic leak after gastrointestinal surgery. Br J Surg. 2001; 88:1157-68.

[3]. Matthiessen P, Hallbo“" “k O, Andersson M, Rutega ${ }^{\circ} \mathrm{rd}$ J, Sjo“dahl R. Risk factors for anastomotic leakage after anterior resection of the rectum. Colorectal Dis. 2004; 6:462-69.

[4]. Alves A, Panis Y, Pocard M, Regimbeau JM, Valleur P. Management of anastomotic leakage after non diverted large bowel resection. J Am Coll Surg. 1999; 189:554-59.

[5]. Sutton CD, Marshall LJ, Williams N, Berry DP, Thomas WM, Kelly MJ. Colo-rectal anastomotic leakage often masqueradses as a cardiac complication. Colorectal Dis. 2004; 6:21-22.

[6]. Oberhofer D, Rumenjak V, Lazic' J, Vucic' N. Inflammatory indicators in patients after surgery of the large intestine. Acta Med Croatica.2006; 60:429-33.

[7]. Karliczek A, Harlaar NJ, Zeebregts CJ, Wiggers T, Baas PC, van Dam GM.Surgeons lack predictive accuracy for anastomotic leakage in gastrointestinal surgery. Int J Colorectal Dis. 2009; 24: 569-76.

[8]. Pepys MB, Hirschfield GM. C-reactive protein: a critical update. J Clin Invest.2003;111:1805-12.

[9]. Woeste G, Mu“ller C, Bechstein WO, WullsteinC.Increased serum levels of C-reactive protein precede anastomotic leakage in colorectal surgery. Word J Surg2010;34:140-46.

[10]. Matthiessen P, Henriksson M, Hallbko"ko"k O, Grunditz E, Nore'n B, ArbmanG.Increase of serum Creactive protein is an early indicator of subsequent symptomatic anastomotic leakage after anterior resection. Colorectal Dis.2010; 10:75-81.

[11]. Almeida AB, Faria G, Moreira H, Pinto-de-Sousa J, Correia-da- Silva P, Costa Maia J.Elevated serum Creactive protein as a predictive factor for anastomotic leakage in colorectal surgery. Int J Surg.2012;10:8791

[12]. Werner J, Hartwig W, Uhl W et al.Useful markers for predicting severity and monitoring progression of acute pancreatitis. Pancreatology.2003; 3:115-27.

[13]. Wullstein C, Drognitz O, Woeste G etal.High levels of Creactive protein after simultaneous pancreas-kidney transplantation predict pancreas graft-related complications and graft survival. Transplantation.2004; 77:60-64.

[14]. Kragsbjerg P, Holmberg H, VikerforsT.Serum concentrations of interleukin-6, tumour necrosis factor-alpha, and Creactive protein in patients undergoing major operations. Eur J Surg.1995; 161:17-22.
[15]. Mustard RA Jr, Bohnen JM, Haseeb S etal.C-reactive protein levels predict postoperative septic complications. Arch Surg.1987; 122:69-73.

[16]. Welsch T, Muller SA, Ulrich A etal.C-reactive protein as early predictor for infectious postoperative complications inrectal surgery. Int J Colorectal Dis .2007;22:1499-1507.

[17]. Welsch T, Frommhold K, Hinz U etal.Persistingelevation of $\mathrm{C}$-reactive protein after pancreatic resections can indicatedeveloping inflammatory complications. Surgery.2008; 143:2028.

[18]. Korner H, Nielsen HJ, Soreide JA et al.Diagnosticaccuracyof C-reactive protein for intraabdominal infections aftercolorectalresections. J Gastrointest Surg.2009; 13:1599-1606.

[19]. Woeste G, Muller C, Bechstein WO etal.Increasedserumlevels of C-reactive protein precede anastomotic leakage incolorectal surgery. World J Surg.2010; 34:140-46.

[20]. Ortega-Deballon P, Radais F, Facy O etal.Creactiveprotein is an early predictor of septic complications after electivecolorectal surgery. World J Surg. 2010; 34:808-14.

[21]. Mackay GJ, Molloy RG, O’Dwyer PJ.C-reactive proteinas a predictor of postoperative infective complications followingelective colorectal resection. Colorectal Dis. E-pub ahead of print.2010.

[22]. Dutta S, Fullarton GM, Forshaw MJ, Horgan PG, McMillan DC.Persistent elevation of C-reactive protein followingesophagogastric cancer resection as a predictor of postoperativesurgical site infectious complications. World J Surg.2011; 35:1017-25.

[23]. Warschkow R, Beutner U, Steffen T, Müller SA, SchmiedBM, Güller U, Tarantino I. Safe and early discharge aftecolorectal surgery due to C-reactive protein: a diagnosticmeta-analysis of 1832 patients. Ann Surg.2012; 256: 245-50.

[24]. Slotwiński R, Olszewski WL, Chaber A, Slodkowski M, ZaleskaM, Krasnodebski IW. The soluble tumor necrosis factorreceptor I is an early predictor of local infective complication after colorectal surgery. J ClinImmunol 2002; 22: 289-96.

[25]. Iversen LH, Thomsen GH, Thorlacius-Ussing O. Systemiccoagulation activation and anastomotic leakage after colorectalcancer surgery. Dis Colon Rectum 1999; 42: 56-65

[26]. M. S. Scepanovic, B. Kovacevic, V. Cijan, A. Antic, Z. Petrovic, R. Asceric, I. KrdzicV. Cuk. C-reactive protein as an early predictor for anastomotic leakagein elective abdominal surgery. Tech Coloproctol 2013; 17:541-47. 